\section{Parameterization of Convective Heat Fluxes over Ile-Ife Using Bowen Ratio, Aerodynamic Gradient and Aerodynamic with Resistance Techniques}

\section{Abstract}

This research parameterized sensible and latent heat fluxes using Bowen Ratio (BR) also known as (Bowen Ratio Energy Balance), Aerodynamic Gradient (AG) and Aerodynamic Resistance (AR) techniques. Energy Residuum as well as Closure fractions were obtained and were used to assess closures for both direct and indirect fluxes. The data used were sourced from the Nigeria Micrometeorological Experiment (NIMEX-1) conducted within the transition period, 2004. The research site is located at the agricultural farm of Obafemi Awolowo University, Ile-Ife, (lat. $7.55^{\circ} \mathrm{N}$, Long. $4.56^{\circ} \mathrm{E}$ ), Nigeria. The results from each of the techniques were correlated with the measured heat fluxes in order to decide the best theoretical approach for the estimation of fluxes over the region of study. BR and AG compared moderately with the measured fluxes. BR scheme overestimated latent heat flux but underestimated sensible heat flux; AG technique slightly underestimated sensible heat flux but strongly underestimated latent heat fluxes with only few days of overestimation of sensible heat flux. AR, on the other hand, underestimated both latent and sensible heat fluxes. The obtained closure for AG proved much closer to the closure obtained from the direct measurement, BR has a better theoretical closure while AR failed as a whole. The trends as well as statistical analysis proved that AG performed best for sensible heat flux while BR presented good results for both latent heat flux and energy closure.

Keywords: Aerodynamic resistance; Bowen ratio; Energy balance; Surface closure; Sensible heat flux; Latent heat flux

\author{
B. Adeyemi, E.O. Ogolo and \\ M.P. Ajakaiye* \\ Department of Physics, Federal University of \\ Technology, Akure, Ondo State, Nigeria
}

\section{*Corresponding author: Ajakaiye MP \\ $\equiv$ muyiwapaul@gmail.com}

Department of Physics, Federal University of Technology, Akure, Ondo State, Nigeria.

Tel: +2348033898917

Citation: Adeyemi B, Ogolo E.O, Ajakaiye M.P (2017) Parameterization of Convective Heat Fluxes over Ile-Ife Using Bowen Ratio, Aerodynamic Gradient and Aerodynamic with Resistance Techniques Appl Sci Res Rev Vol. 4 No.2:11

Received: September 13, 2017; Accepted: October 24, 2017; Published: October 31, 2017

\section{Introduction}

The role of convective heat fluxes in the tropospheric processes cannot be overemphasized. Land surface heat fluxes are essential components of the water and energy cycles and govern the interactions between the Earth surface and the atmosphere. Carlos et al. and Grimond et al. stated that the knowledge of the sensible heat flux and atmospheric stability is a prerequisite of models to calculate air pollution dispersion, urban mixing depth and Mesoscale air flow [1,2]. Katavoutas et al. investigated thermal comfort in the hot outdoor environment under unsteady conditions [3]. Their results indicate that human heat flux fluctuates due to fluctuations in air temperature and other atmospheric variables such as humidity. Hence, there is a dependent of human comfort on surface convective heat fluxes. Convective heat fluxes are the responses of the forcing net radiation flux received at the land-air boundary. Jegede, Balogun, and Ohmura are the earlier researchers who attempted the estimation of convective heat fluxes using indirect flux-gradient and Bowen ratio methods [4-7]. In 2012, Omokugbe et al. investigated the portioning of the net radiation flux and the surface energy fluxes using the Eddy Covariance method and presented that the midnight and the early morning hours of the days recorded negative values for the net radiation but increased at 7:30 $\mathrm{h}$ to peak values ranging from $317 \mathrm{~W} / \mathrm{m}^{2}$ to $586 \mathrm{~W} / \mathrm{m}^{2}$ [8]. As good as direct measurement of heat fluxes has been, it is important to stress that the cost of acquiring, installing and maintaining stations for direct measurement (using eddy covariance method) is beyond 
the reach of many researchers. This necessitates the indirect approach of estimating convective heat fluxes from atmospheric parameters as inputs. Another key problem with eddy covariance method, according to Jerald et al. is its sensitivity to fetch effect (the distance wind travels (over homogeneous surface such as water) before meeting an obstacle). McNeil and Shuttleworth compared heat fluxes measured by EC and BR methods over a pine forest and observed that the sensible heat flux by $B R$ technique is $24 \%$ less than that from EC methods. Estimates from latent and sensible heat fluxes from the EC were $23 \%$ and $33 \%$ less than those from BR system. Hence, this research compared the results from the three schemes with the measured. It was obvious, far back as in the 1980s that the sum of the energy components is either greater or less than the net radiation flux. In consequence, there is imbalance or non-closure between the incoming radiation and the outgoing sum of the latent, sensible and the ground heat fluxes. It was observed that the sum of the net radiation flux and ground heat flux is greater than the sum of the latent and sensible heat fluxes [9]. Foken stated that the typical residual energy balance closure in the day time is found to be between $50-300 \mathrm{~W} / \mathrm{m}^{2}$, which he associated to errors in latent, sensible, ground and net radiation fluxes as well as the variation in the vertical and horizontal height scales.

\section{Instrumentation, Data Acquisition and Site Description}

The archived data of the meteorological variables obtained from the Nigeria Micrometeorological Experiment (NIMEX -1) campaign carried out at the site between $24^{\text {th }}$ of February to $10^{\text {th }}$ of March 2004, are collected. The data covered a period of 15 days. The micrometeorological parameters measured include: dry and wet air temperatures obtained with Frankenberger Psychrometer by Theodor Friedrichs, soil temperature measured with PT $100 \Omega$ (ventilated) by Vector instrument, surface temperature by (Infrared Pyrometer KT 1562D by Heitronics), net wave radiation obtained with Net radiometer REBS Q7 NRLITE CRN-1, 3-dimensional wind speeds obtained with Ultrasonic Anemometer USA-1 by METEK, air pressure measured with

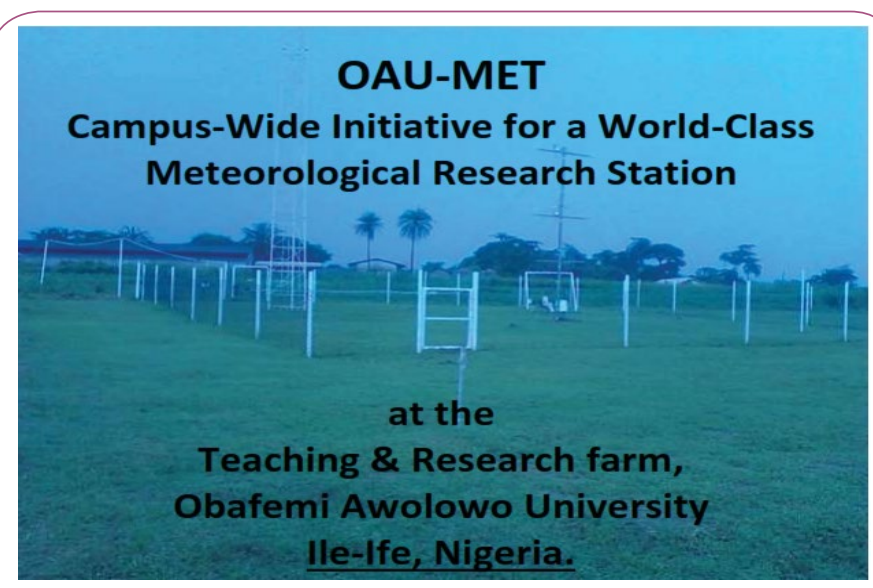

Figure 1 Meteorological site of Obafemi University, lle-Ife, Nigeria.
Capacitive Barometer by Ammonit, long wave and short wave radiations. Detailed information of the measurement procedures as well as experimental setups is in the conference proceedings of NIMEX-1 at Ile-Ife, Nigeria, 2004 (Figure 1) [10].

\section{Theoretical Methods of Estimating Convective Heat Fluxes}

Bowen Ratio energy balance technique (BR): Bowen ratio method is one of the oldest methods for estimating surface heat fluxes. The word ratio here compares sensible heat flux to latent heat flux. This is defined as $[5,6,10]$

$\beta=\frac{\text { Sensible heat flux }}{\text { Latent heat flux }}$

This method works based on certain assumptions, which are:

(i) Fluxes are one-dimensional only with no horizontal gradients and that measurement sensors are located within the equilibrium sub-layer where the fluxes are constant with height (Dyer and Hicks).

(ii) Land surface is assumed homogeneous with respect to sources of heat, water vapor and momentum transfer [11].

(iii) The turbulent exchange coefficient of heat and water vapor are assumed equal. Therefore, equal surface roughness length is taken for heat and water vapor.

Under the above conditions, Bowen ratio can be calculated from the difference in actual air temperature $\Delta T_{\alpha}$ and actual vapor pressure change $\Delta e_{\alpha}$ over a vertical air column. According to Euser et al. [12]

$\beta=\gamma \frac{\Delta T_{\alpha}}{\Delta e_{\alpha}}$

where $r=0.071 \mathrm{khPa}{ }^{0} \mathrm{C}^{-1}$, is the Psychrometric constant for wind speed less than $3.0 \mathrm{~m} / \mathrm{s}$. Using measurements from dry and wet surface, temperature and the actual water vapor $\Delta e_{\alpha}$ can be calculated using Allen et al. [13]

$e_{a}=e_{s}-\gamma\left(T_{\alpha}-T_{w}\right)$

where; $e_{s}$ is the saturation vapor pressure that can be obtained using Allen et al.

$e_{s}=0.61 e^{\frac{1.73 T_{\alpha}}{273+T_{w}}}$

Taking measurement at any two reference height 1 and 2 with equations ( 2 ) becomes Euser et al.

$\beta=\gamma \frac{T_{\alpha_{1} 2}-T_{\alpha_{1} 1}}{\left(e_{s_{1} 2}-e_{s_{1} 1}\right)-\gamma\left(T_{\alpha_{1} 2}-T_{\alpha_{1} 1}\right)+\gamma\left(T_{w_{1} 2}-T_{w_{1} 1}\right)}$

Equation (5) can be written as;

$\beta=\gamma \frac{\Delta T_{\alpha}}{\left(\Delta e_{s}\right)-\gamma\left(\Delta T_{\alpha}\right)+\gamma \Delta T_{w}}$

where each term retains its usual definition. It is observed here that the Bowen Ratio depends only on the Psychometric values of the instrument 
With Bowen ratio $\beta$ obtained, the available energy $\left(R_{n}-G\right)$ is partitioned into sensible and latent heat fluxes according to the equations below.

$H_{L}=\frac{\left(R_{n}-G\right)}{1+\beta}$

$H_{S}=\frac{\left(R_{n}-G\right)}{1+\frac{1}{\beta}}$

where $\mathrm{G}$ is the ground heat flux, sometimes represented by $H_{G}$ and $R_{n}$ is the net radiation flux. Each of the surface energy fluxes is calculated in $\mathrm{Wm}^{-2}$

Aerodynamic Gradient Technique (AGT): One of the widely accepted methods of estimating surface heat fluxes is the Eddy covariance method. The basic foundation of this method rests on the work of Reynold, who came up with decomposition scheme which helps to isolate turbulent component from the mean value of a variable [14].

From the covariances only, sensible and latent heat fluxes are estimated using the equations below.

$H_{S}=\rho C_{p} \overline{w T}$

$H_{L}=\rho C_{p} \overline{w q}$

$\rho$ is the air density, $C_{p}$ is the specific heat capacity of dry air at constant pressure.

$\rho=1.225 \mathrm{kgm}^{-3} C_{p}=1004.67 \mathrm{Jkg}^{-1} \mathrm{~K}^{-1}[15]$

However, for profile measurement, the covariances are obtained as shown below

$\overline{w^{\prime} T^{\prime}}=-K_{0} u_{*} \frac{\Delta T}{\Delta \ln z}$

$\overline{w^{\prime} q^{\prime}}=-K_{0 E} u_{*} \frac{\Delta q}{\Delta \ln z}$

where $\mathrm{u}_{*}$ is the frictional velocity given by the expression below, $K_{0}$ and $K_{0 E}$ are the eddy diffusivities of heat and water, respectively.

Under stable condition,

$K_{E}=K_{0}=1.25$

$u_{*}=k \frac{\Delta u}{\Delta \ln z}$

Since specific humidity was not measured directly, it can be parameterized from dry and wet bulbs temperatures using equation 15 [16].

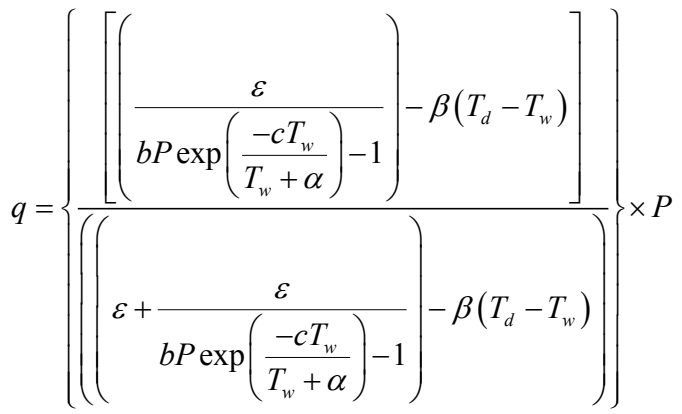

where $b, c, \varepsilon, \alpha$ and $\beta$ are constants which are experimentally determined. For general purpose;

$\mathrm{b}=1.631 \mathrm{kPa}^{-1}, \mathrm{c}=17.67$ and $\left.\varepsilon=0.622 \mathrm{~g} / \mathrm{g}, \beta=4.0224 * 10^{-4} \mathrm{~g}\right) /{ }^{\circ} \mathrm{C}$, and $\alpha=243.5^{\circ} \mathrm{C}$

$\mathrm{T}_{\mathrm{w}}=$ wet bulb temperature, $\mathrm{T}_{d}=$ dry bulb temperature, $\mathrm{P}=$ ambient pressure and $q$ is the specific humidity

$\alpha=243.5{ }^{\circ} \mathrm{C}$

Aerodynamic with Resistance Technique (ART): Aerodynamic technique deals with the surface diffusivity of matter at the surface layer. Hence, equations (1) and (2) can be expressed in terms of Aerodynamic equations as:

$H_{S}=\rho C_{p} \frac{T_{0}-T_{\alpha}}{r_{a}}$

$H_{L}=\rho C_{p} \frac{q_{0}-q_{\alpha}}{r_{a}}$

where $r_{\alpha}$ is the aerodynamic resistance. $T_{0}, T_{\alpha}, q_{0}$ and $q_{\alpha}$ are the respective reference surface temperature, air temperature, surface humidity and air humidity.

where $\mathrm{k}$ is the Von Kaman constant, $\theta_{1}$ and $\theta_{2}$ are the surface air temperatures at two heights $\mathrm{z}_{1}$ and $\mathrm{z}_{2}$ while $\mathrm{u}_{1}$ and $\mathrm{u}_{2}$ are the respective wind speeds at sea level while $e_{a 1}$ and $e_{a 2}$ are the actual vapor pressure measured at different the same altitudes $\mathrm{z}_{1}$ and $\mathrm{z}_{2}$, respectively.

Where $\rho$ is the air density, $C \rho$ is the specific heat capacity of air at constant pressure, $T_{0}$ is the surface (skin) temperature, and $T_{z}$ is the temperature of the air at position $z$ above the surface, $q$ is the specific humidity, $r_{\alpha}$ remains the aerodynamic resistance in $\mathrm{sm}^{-1}$. It is the diffusion resistance to sensible heat transfer between the surface and an altitude $z$ above the surface [17].

$r_{a}=\frac{\left[\ln \left(\frac{z}{z_{0}}\right)+\psi H\right]\left[\ln \frac{Z}{z_{0}}+\psi M\right]}{k^{2} u_{*}}$

$z=\sqrt{z_{1} z_{2}}$

but under stable condition [18];

$\psi_{H}=\psi_{M}=\frac{-S_{z}}{L}$

where $\mathrm{L}$ is the Obukhov length, $\mathrm{z}$ is height, $\psi_{M}=$ is the transfer of heat and

$\psi_{M}=$ momentum transfer of water.

The aerodynamic method is one of the most widely used indirect methods of computing momentum and sensible heat transfers at the lower surface of the planetary boundary layer. This method only requires atmospheric measurement of input variables at a single altitude alongside with surface properties such as the roughness length as well as the skin temperature (for heat flux). For a very low surface, the equations below are sufficient for computing the fluxes [19-21].

$\psi_{M}=\psi_{H}=-5 \frac{Z}{L}$ 
where $\mathrm{z}$ is the measurement height, $\mathrm{L}$ is the Obukhov length.

Monnin and Obukhov (1954), promulgated, an accepted model for estimating $L$ as given below $[14,22]$ :

$$
L=\frac{\overline{\Delta T} u_{*}^{a}}{\operatorname{kg}\left(\overline{w^{\prime} T_{0}^{\prime}}\right)}
$$

where $\Delta T$ and $\overline{w^{\prime} T_{0}^{\prime}}$ are the variance and the covariance of temperature and wind speed, while $\mathrm{g}$ is the acceleration due to gravity, $u_{*}$ is the frictional velocity, $\mathrm{k}$ is the von Kaman constant (taken as 0.4) [14].

\section{Results and Discussions}

Analysis of all input variables can be obtained from Jegede et al. [10]. However, other needed parameters required for estimation of sensible and latent heat fluxes were parameterized from these meteorological variables. Hence, only the estimated heat fluxes as well as their closure are hereby discussed.

Estimated convective heat fluxes: Figure $2 \mathbf{a}$ and $\mathbf{b}$ show the daily trend of the estimated sensible and latent heat fluxes from the $A G, B R$ and OBS (Observed from direct measurement by eddy covariance) heat fluxes. It is observed that there was no much difference in the magnitudes of the estimated and measured heat fluxes during the early morning hours. This may be due to the absence of turbulence at such times. However, after sun rise, evolution of turbulence began due to increase intensity of the net solar radiation which triggers other atmospheric parameters into response.

From the results, $A G$ yielded a maximum sensible heat flux of $254.37 \mathrm{~W} / \mathrm{m}^{2}$ on Julian day 64 at 11:00 LT with a minimum day time value of $12.0 \mathrm{~W} / \mathrm{m}^{2}$. Also, mean sensible heat ranges from $0.50 \mathrm{~W} / \mathrm{m}^{2}$ to $112.00 \mathrm{~W} / \mathrm{m}^{2}$. Latent heat flux has a maximum value of $300.87 \mathrm{~W} / \mathrm{m}^{2}$ which is $46.89 \mathrm{~W} / \mathrm{m}^{2}$ more than the maximum value of sensible heat flux which is due to the synoptic of the day. The daily mean values range from $10.84 \mathrm{~W} / \mathrm{m}^{2}$ to $114.15 \mathrm{~W} /$ $\mathrm{m}^{2}$. Evaluation of estimated heat fluxes with respect to wet day (56), dry day (58) and cloudy day (68) revealed that the mean sensible heat fluxes for the above reference days were 106.24 $\mathrm{W} / \mathrm{m}^{2}, 110.13 \mathrm{~W} / \mathrm{m}^{2}$ and $71.83 \mathrm{~W} / \mathrm{m}^{2}$, respectively as against the observed values of $143.05 \mathrm{~W} / \mathrm{m}^{2}, 86.69 \mathrm{~W} / \mathrm{m}^{2}$ and 85.91 $\mathrm{W} / \mathrm{m}^{2}$, respectively for the same set of days. The mean value for wet day is $36.805 \mathrm{~W} / \mathrm{m}^{2}$ less than the observed. Hence, AG has under estimated mean flux for the wet day by $36.80 \mathrm{~W} / \mathrm{m}^{2}$. This maybe as a result of the fact that sonic anemometer cannot operate properly when it is wet (Jerald, 2002). For latent heat flux, the daytime mean values for the selected synoptic days were respectively $47.97 \mathrm{~W} / \mathrm{m}^{2}, 72.24 \mathrm{~W} / \mathrm{m}^{2}$ and $46.46 \mathrm{~W} / \mathrm{m}^{2}$ while the observed were $11.40 \mathrm{~W} / \mathrm{m}^{2}, 10.23 \mathrm{~W} / \mathrm{m}^{2}$ and $123.08 \mathrm{~W} / \mathrm{m}^{2}$, respectively.

The roughness length, $z_{0}$ was obtained from the plot of $/ n z$ against wind speed (u), [14] and was found to be around $0.011 \mathrm{~m}$. The hourly series of the estimated fluxes of sensible and latent heat fluxes are shown in Figures $\mathbf{2}$ and 3, respectively. In magnitude, Aerodynamic Resistance (AR) scheme performed very poorly for both latent and sensible heat fluxes. The failure of aerodynamic scheme in estimating turbulent fluxes maybe adduced to weak wind speed which is generally a prominent feature of the tropical area [8]. Maximum values of sensible and latent heat fluxes obtained are $1.88 \mathrm{~W} / \mathrm{m}^{2}$ which occurred on day 64 of the year at around $12.00 \mathrm{~h}$ and $0.38 \mathrm{~W} / \mathrm{m}^{2}$ on day 68 around $11: 00 \mathrm{~h}$, respectively. The estimations revealed minimum values of -37.05 $\mathrm{W} / \mathrm{m}^{2}$ for sensible heat flux at 19:00 $\mathrm{h}$ and $-36.00 \mathrm{~W} / \mathrm{m}^{2}$ for latent heat flux at about the same time. This result has shown that AR is not a good scheme for the theoretical estimation of convictive heat fluxes in the tropics with low wind speed.

The Bowen ratio obtained using equation 3.1 to equation 3.8 was combined with the available energy $\left(R_{N}-G\right)$ to obtain the sensible and latent heat fluxes using equation 3.7 and equation 3.8, respectively (Figures $\mathbf{2}$ and $\mathbf{3}$ ). It was observed that during the late night and early morning hours, estimated heat fluxes by $B R$ were fairly constant $(00.00 \mathrm{LT}-7.00 \mathrm{LT})$. Evolution of convective heat began at about $08.00 \mathrm{LT}$, attained peak values in the late afternoon and descended slowly back to constant values at sunset to late night hours. The maximum day time sensible and latent heat fluxes obtained were $69.36 \mathrm{~W} / \mathrm{m}^{2}$ and $469.54 \mathrm{~W} / \mathrm{m}^{2}$, respectively. These values were respectively $203.48 \mathrm{~W} / \mathrm{m}^{2}$ less and $168.94 \mathrm{~W} / \mathrm{m}^{2}$ more than the measured sensible and latent heat fluxes. This proved that BR partitioned the available energy differently into sensible and latent heat fluxes. While latent heat was overestimated, sensible heat flux was underestimated. The day time mean values estimated for sensible and latent heat fluxes were respectively, $41.60 \mathrm{~W} / \mathrm{m}^{2}$ and $220.94 \mathrm{~W} / \mathrm{m}^{2}$. (Figures 2a-d and 3a-d).

\section{Comparative performance of the calculated values of convective heat flux using different techniques}

Figure 4a-c show the scatter plots of the estimated sensible heat fluxes against observed sensible while Figure $\mathbf{4 d - f}$ present the scatter plots of the estimated latent heat flux against the observed latent heat flux for day 55 only. For sensible heat flux $R^{2}$ for $B R, A G$ and $A R$ have mean values of $0.8023,0.6383$ and 0.1045 respectively. Mean values of $R$ for $B R, A G$ and $A R$ are $0.8872,0.7838$ and 0.2968 respectively. The values of $R$ and $R^{2}$ for $A G$ and $B R$ are good enough for acceptability while those of $A R$ revealed weak correlations. For latent heat flux, the mean values of $R^{2}$ for $B R, A G$ and $A R$ are $0.6998,0.4456$ and 0.2373 while the corresponding values of $R$ are $0.7873,0.6261$ and 0.4634 respectively. Comparing the values of $R$ for sensible and latent heat fluxes, it was observed that $B R$ and $A G$ estimated sensible heat flux better than latent heat flux while AR estimated poorly for both sensible and latent heat fluxes. It can therefore be established that while $A G$ and $B R$ are good schemes for theoretical estimation of convective heat fluxes, $A R$ is not. However, $A G$ presented better sensible heat flux than $B R$ while $B R$ estimated latent heat flux better than AG. Figure 4a-c.

Energy residuum and closure fraction: In order to further investigate the performances of the schemes, energy residuum was obtained for each of the schemes as well as the measured as the difference between the net radiation flux and the components of the radiation flux (the ground, the latent and the sensible heat fluxes). On the other hand, the closure fraction was obtained as the plot of the available energy to the turbulent fluxes as given 

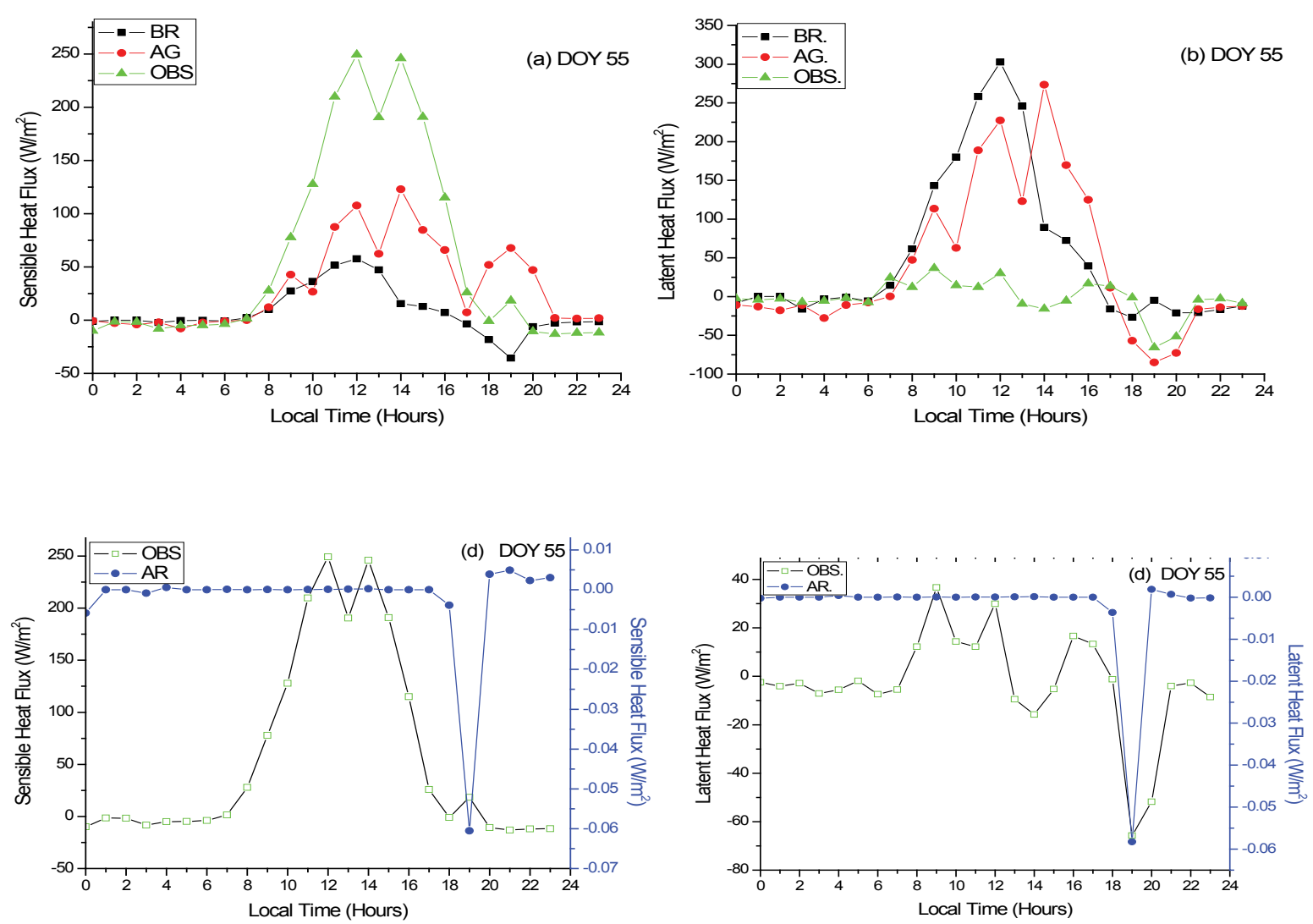

Figure 2 (a-d) Comparative Distribution of Estimated Convective Heat Fluxes for Ile-Ife for day 55: (a) Sensible Heat Flux for Aerodynamic Gradient (AG), Bowen ratio (BR) and Observed (OBS); (b) Latent Heat for (AG), BR and Observed (OBS); (c) Sensible for Aerodynamic $(A R)$ and (OBS); (d) Latent Heat flux for (AR) and (OBS).
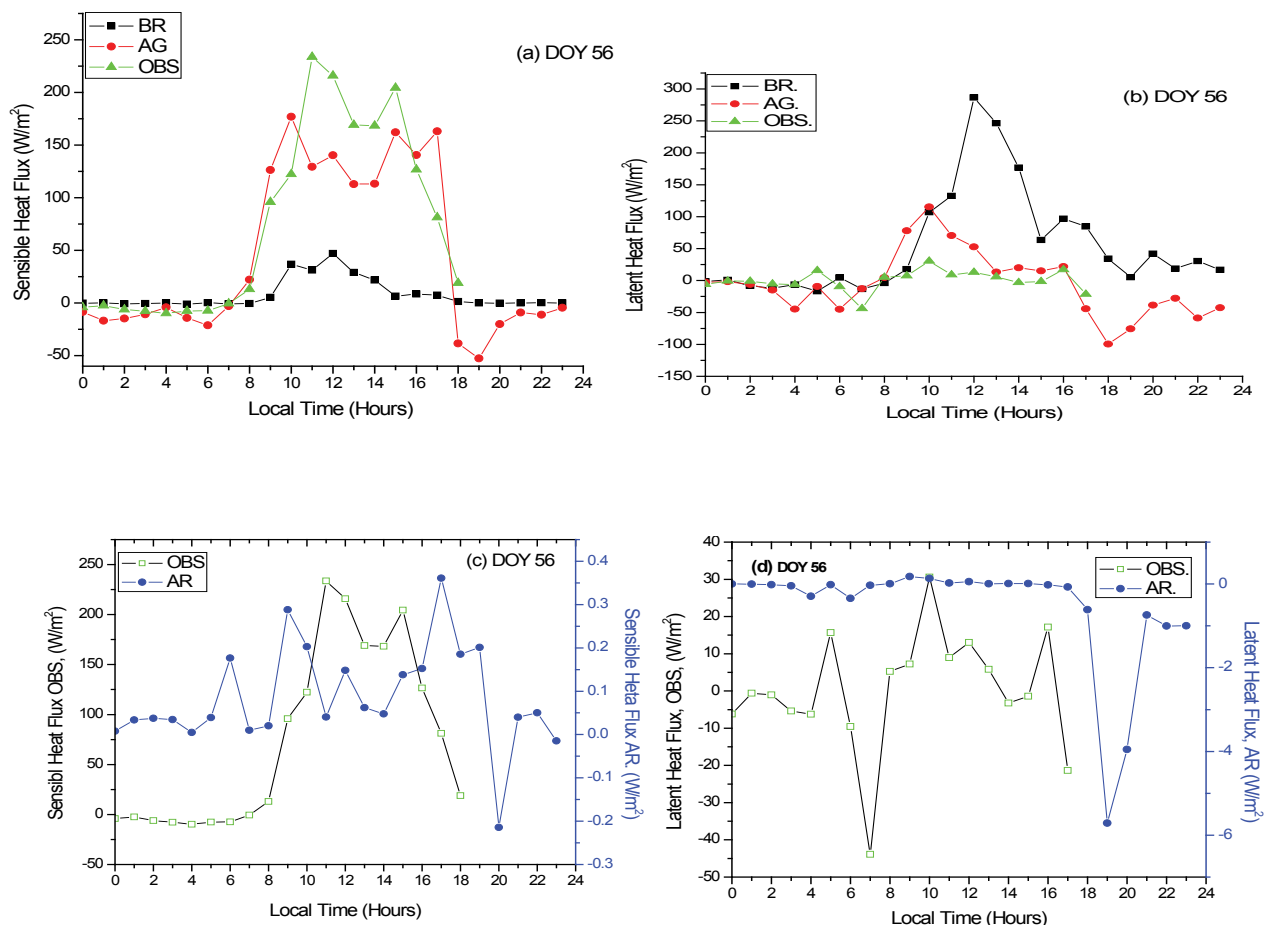

Figure 3 (a-d) Comparative Distribution of Estimated Convective Heat Fluxes for Ile-Ife for day 56: (a) Sensible Heat Flux for Aerodynamic Gradient (AG), Bowen ratio (BR) and Observed (OBS); (b) Latent Heat for (AG), BR and Observed (OBS); (c) Sensible Heat Flux for Aerodynamic (AR) and (OBS); (d) Latent Heat Flux for (AR) and (OBS). 

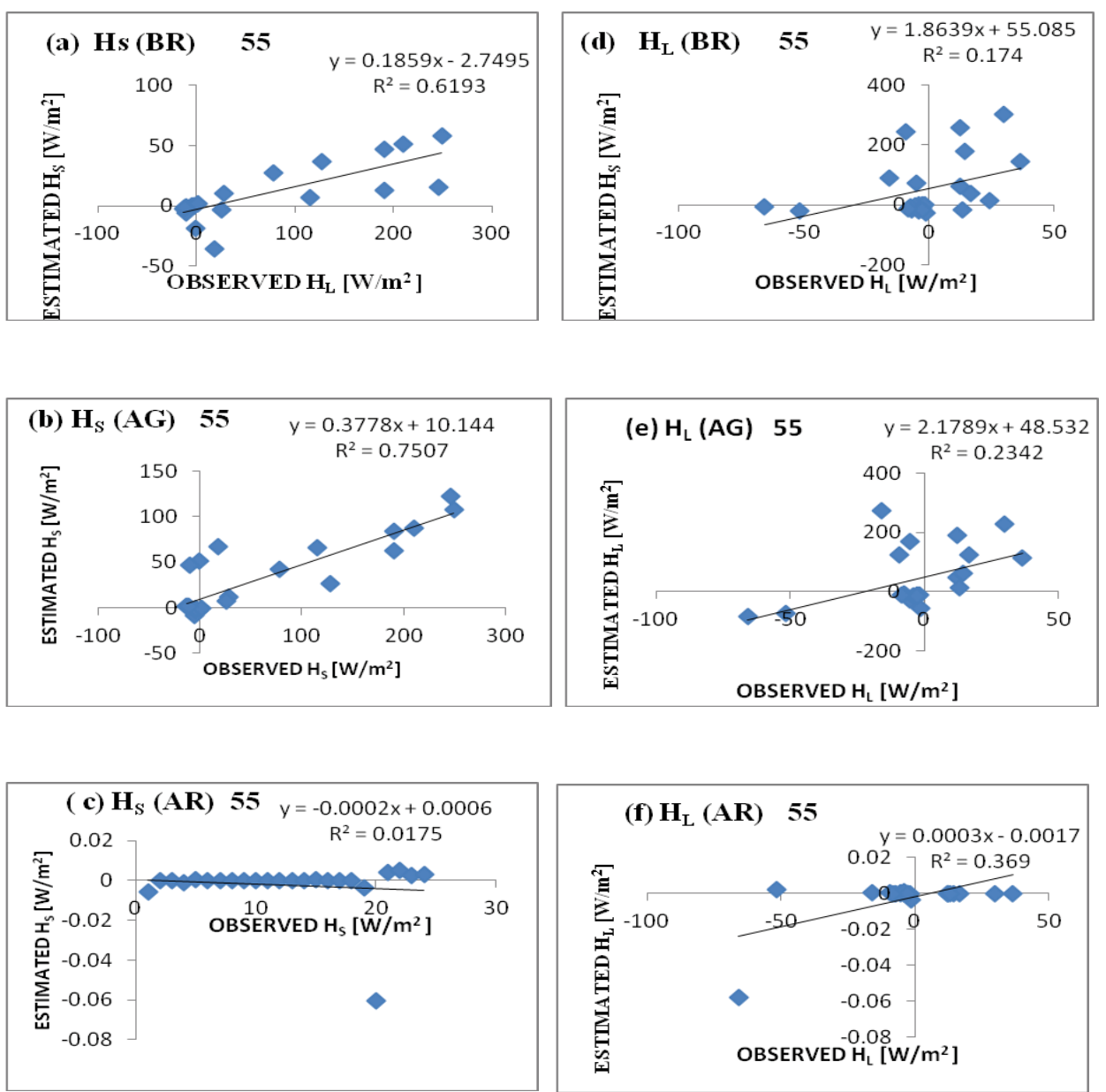

Figure 4 (a-f) Scatter plots between the Estimated and the Observed Sensible and Latent Heat Fluxes $\left(\mathrm{H}_{\mathrm{S}}\right.$ and $\left.\mathrm{H}_{\mathrm{L}}\right)$, respectively for lle-Ife for day 55 using $B R, A G$ and $A R$.

Table 1 Correlation parameters from the comparison of estimated with measured sensible heat fluxes for lle-Ife; where $\alpha$ is the value of the estimated heat flux corresponding to the least value of the measured flux, $\beta$ is the Gradient, $R^{2}$ is the coefficient of determination and $R$ is the correlation coefficient.

\begin{tabular}{|c|c|c|c|c|c|c|c|c|c|c|c|c|}
\hline \multirow[t]{2}{*}{ Days } & \multicolumn{4}{|c|}{ BR } & \multicolumn{4}{|c|}{ AG } & \multicolumn{4}{|c|}{$\mathrm{AR}$} \\
\hline & $\alpha\left(W / m^{2}\right)$ & $\beta$ & $\mathrm{R}^{2}$ & $R$ & $\alpha\left(W / m^{2}\right)$ & $\beta$ & $\mathrm{R}^{2}$ & $R$ & $\alpha\left(W / m^{2}\right)$ & $\beta$ & $\mathrm{R}^{2}$ & $R$ \\
\hline 55 & -2.7495 & 0.1859 & 0.6193 & 0.787 & 10.144 & 0.3778 & 0.7507 & 0.8664 & 0.0006 & -0.0002 & 0.0175 & 0.1323 \\
\hline 56 & $-61,553$ & 0.1385 & 0.6686 & 0.8177 & 3.6045 & 0.7744 & 0.7502 & 0.8661 & -0.0126 & 0.0107 & 0.3795 & 0.616 \\
\hline 58 & 6.7986 & 0.1198 & 0.2764 & 0.5257 & 1.3294 & 1.0748 & 0.4056 & 0.6369 & 0.3583 & -0.0019 & 0.1224 & 0.3499 \\
\hline 59 & 2.8345 & 0.2119 & 0.9338 & 0.9663 & 9.2062 & 0.2082 & 0.4544 & 0.6741 & -0.1505 & 0.0009 & 0.014 & 0.1183 \\
\hline 60 & 5.8313 & 0.189 & 0.864 & 0.9295 & 1.3294 & 1.0748 & 0.4056 & 0.6369 & 0.3583 & -0.0019 & 0.1224 & 0.3499 \\
\hline 61 & 1.4876 & 0.3064 & 0.9746 & 0.9872 & 0.2375 & 0.6277 & 0.8081 & 0.8989 & -0.0628 & 0.0015 & 0.1763 & 0.4199 \\
\hline 62 & 0.4524 & 0.2939 & 0.9836 & 0.9918 & 13.531 & 0.8074 & 0.8607 & 0.9277 & -0.0303 & 0.0005 & 0.0773 & 0.278 \\
\hline 63 & 7.7883 & 0.3133 & 0.879 & 0.9376 & 14.297 & 0.8231 & 0.6405 & 0.8003 & -1.3969 & 0.0163 & 0.0674 & 0.2596 \\
\hline 64 & 3.1606 & 0.3116 & 0.753 & 0.8678 & -4.6389 & 1.6639 & 0.8033 & 0.8963 & -0.7616 & 0.0178 & 0.1211 & 0.348 \\
\hline 65 & 6.6181 & 0.4175 & 0.9532 & 0.9763 & 4.0217 & 2.0293 & 0.8872 & 0.9419 & -0.8395 & 0.0193 & 0.0623 & 0.2496 \\
\hline 66 & 5.6644 & 0.4167 & 0.8754 & 0.9356 & -30.493 & 2.3782 & 0.8563 & 0.9254 & -0.9836 & 0.0212 & 0.1089 & 0.33 \\
\hline 67 & 6.7959 & 0.4547 & 0.9336 & 0.9662 & -64.683 & 1.4414 & 0.5154 & 0.717914 & -4.2825 & 0.0376 & 0.0705 & 0.2655 \\
\hline 68 & 0.0384 & 0.5336 & 0.7137 & 0.8448 & 0.9047 & 0.0065 & 0.1602 & 0.40025 & -4.1016 & 0.0258 & 0.0199 & 0.1411 \\
\hline
\end{tabular}


by Jerald et al. It was observed that, aerodynamic Resistance technique (AR) has the highest value of residual energy with daily mean ranging from $60.39 \mathrm{~W} / \mathrm{m}^{2}$ to $123.26 \mathrm{~W} / \mathrm{m}^{2}$. Aerodynamic Gradient (AG) presented daily mean range from $-84.19 \mathrm{~W} / \mathrm{m}^{2}$ to $93.22 \mathrm{~W} / \mathrm{m}^{2}$. Bowen Ratio (BR) daily mean ranges from -5.05 $\mathrm{W} / \mathrm{m}^{2}$ to $0.00 \mathrm{~W} / \mathrm{m}^{2}$ while the measured (OBS) has daily mean value from $-37.62 \mathrm{~W} / \mathrm{m}^{2}$ to $52.53 \mathrm{~W} / \mathrm{m}^{2}$. The result presented by AR has only positive values, this maybe which is due to the wide range of underestimation. This implies that there was a mixture of overestimations and underestimation. The above results have further proved that AR would not serve as a reliable scheme for theoretical estimation of convective fluxes due to the low wind speed of the research site.

The mean closure fractions for BR, AG, AR and OBS are 99.89 $\%, 45.94 \%, 0.41 \%$ and $92.88 \%$, respectively. The estimated coefficient of correlations for $B R, A G$ and $A R$ were found to have the following respective ranges; $0.9237-0.076,0.8927-$ 0.0678 and $0.3995-0.031$. However, closure fraction obtained by AG was found to have a better practical agreement with the measured than others. Correlation coefficient and coefficient of determination obtained by each model presented good ranges for BR and AG but were however, very poor for AR.

\section{Summary and Conclusions}

The purpose of this research was to identify the most reliable theoretical method of estimating sensible and latent heat fluxes from more routinely atmospheric variables using theoretical approaches. Results obtained from each of the scheme revealed

\section{References}

1 Carlos J, Catherine P, Filine A (2009) Toward an estimation of global land surface heat fluxes from multisatellite observations. J Geophys Res 114: D06305.

2 Grimmond CSB, Oke TR (2002) Turbulent heat in urban areas: Observations and a Local-Scale Urban Meteorological Parameterization Scheme (LUMPS). J Applied Meteorology 41: 1-7.

3 Katavoutas G, Flocas HA, Tsitsomitsiou (2014) Thermal comfort in hot outdoor environment under unsteady conditions. Advances in Meteorology, Climate and Atmospheric Physics, Greece, 2: 195-200.

4 Jegede 00 (1997) Fluxes of sensible in the surface layer estimated from the profile measurements of wind and temperature at a tropical station. Atmosfera 10: 213-223.

5 Balogun AA, Foken Th, Jegede OO, Olaleye JO (2002a) Estimation of sensible and latent heat fluxes over bare soil using Bowen ratio energy balance method at humid tropical site. J Afri Meteorol Sci 5: 63-71.

6 Balogun AA, Jegede OO, Foken Th, Olaleye JO (2002b) Comparison of two Bowen ratio methods for estimating sensible and latent heat fluxes at lle-Ife. J African Meteorol Soc 5: 63-69.

7 Ohmura A (1982) Object criteria for rejecting data for Bowen Ratio flux calculations. J Appl Meteorol 31: 595-598.

8 Omokungbe OR, Ayoola MA, Jegede OO (2012) Diurnal characteristics of the surface energy fluxes at a tropical site in lle-Ife, Nigeria. Ife J Science: 14: 195-206. that none of the models performed convincingly good for both sensible and latent heat fluxes. AG yielded a good estimation for sensible heat flux with a percentage difference of about 13.0\%. However, AG performed weakly for latent heat flux with a percentage difference of about $53 \%$. The Bowen Ratio Energy Balance Technique presented poor sensible heat flux with a percentage difference of $240 \%$ (an under estimation) and latent heat flux with a difference of about $36 \%$. Aerodynamic with resistance Scheme failed for both latent and sensible heat fluxes. From the above percentage difference, it is clear that Bowen Ratio Technique proved more reliable only for latent heat flux while Aerodynamic Gradient is efficient in estimating sensible heat flux. Hence, the two approaches are good for theoretical approach for estimating heat fluxes in the order of performances presented in this research. The need, therefore, for the modification of the Bowen Ratio Technique as literature has it, is a necessity. Aerodynamic with resistance failed altogether for both sensible and latent heat fluxes; which was adduced to the relative poor wind speed or model's deficiency in application to the site of measurement. Table 1 below shows the summary of the comparing of the estimated (from models) with the measured (Table 1).

\section{Acknowledgement}

The authors sincerely appreciate Prof. O. O. Jegede from the Department of Physics, Obafemi Awolowo University, IleIfe, Nigeria, and Prof. A. A. Balogun from the Department of Meteorology, Federal University of Technology, Akure, Nigeria, for their salient contributions.

9 Jerald $A B$, Kenneth $C C$ (2002) Examination of the surface energy budget: A Comparison of Eddy-Correlation and Bowen Ratio Measurement System. J Hydrometeorol 4: 160.

10 Jegede OO, Mauder M, Okobgue EC, Foken T, Balogun EE, et al. (2004) The Nigeria Meteorological Experiment (NIMEX-1): An Overview. Ife J Science 6: 191-202.

11 Todd RW, Evett SR, Howell TA (2000) The Bowen ratio-energy balance method for estimating latent heat flux of irrigated alfalfa evaluated in a semi-arid environment. Agric Forest Meteorol 103: 335-348.

12 Euser T, Luxemburg WMJ, Everson CS, Mengistu MG, Clulow AD, et al. (2014) A new method to measure Bowen ratios using highresolution vertical dry and wet bulb temperature profiles. J Hydrol Earth Syst Sci 18: 2021-2032.

13 Allen RG, Jensen ME, Wright JL, Burman RD (1989) Operational estimates of reference evapotranspiration. Agron J 81: 650-662.

14 Arya $P(2001)$ Introduction to Micrometeorology. $2^{\text {nd }}$ edition, Academic Press, USA, 79: 11-13.

15 Glickman TS (2000) Glosssary of Meteorology. Am Meteorol Soc, Boston, MA, USA.

16 Stull RB (2000) Meteorology for Scientist and Engineers. $2^{\text {nd }}$ Edition, United States.

17 Kalma JG (1989) A Comparison of expression for the aerodynamic resistance to sensible heat transfer. CSIRO Division of Water Resources Technical Memorandum, 89/6, pp: 11.

18 Charnock H (1955) Wind stress on water surface. Quart J Roy Meteorol Soc 81: 639-642. 
19 Webb EK (1970) Profile Relationship: The -Linear Range, and Extension to Strong Stability. QJ Meteorol Soc 96: 67-90.

20 Businger JA, Wyngaard JC, Izumi Y, Bradley EF (1971) Flux profile relationships in atmospheric surface layer. J Atmos Sci 28: 181-189.
21 Oladosu OR, Jegede OO, Sunmonu LA, Adediji AT (2007) Bowen ratio estimation of surface energy fluxes in a humid tropical agricultural site, lle-If, Nigeria. Indian J Radio and Space Physics 36: 213-218.

22 Monin AS, Obukhov AM (1954) Basic laws of turbulence mixing in the atmosphere near the ground. Tr Akad Nauk SSSR Geofiz Inst. 